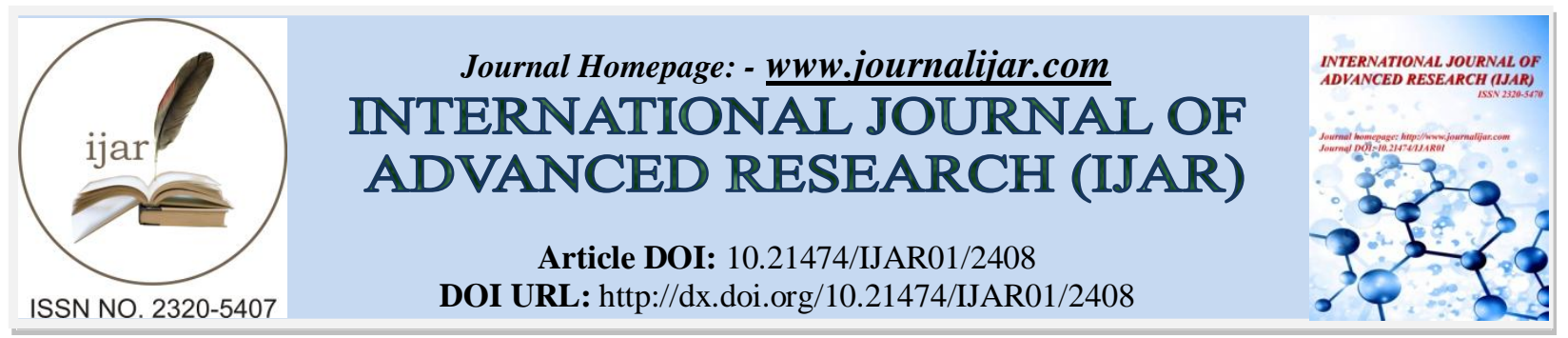

RESEARCH ARTICLE

\title{
EVALUATION OF HYDROGEN PEROXIDE SCAVENGING ACTIVITY OF METANOLIC EXTRACTS OF MORINGA (M. STENOPETALA) LEAVES.
}

\author{
Marye Mulugeta Kassaw ${ }^{*}$, Tamiru Gashaw Gete ${ }^{1}$ and Amha Admasie ${ }^{2}$. \\ 1. College of Natural and Computational Sciences, Chemistry of Department Wolaita Sodo University, \\ Ethiopia. \\ 2. College of Health Sciences, School of Public Health Wolaita Sodo University, Ethiopia.
}

\section{Manuscript Info}

Manuscript History

Received: 20 October 2016

Final Accepted: 22 November 2016

Published: December 2016

Key words:-

Moringaceae stenopetala, soxhlet extraction, methanol, $\mathrm{H} 2 \mathrm{O} 2$

\section{Abstract}

Background:- The aim of this research is to determine hydrogen peroxide scavenging of Moringa stenopetala methanol extracts of leaves. Moringaceae leaves are used in traditional medicine in the treatment of chronic heart failure, high blood pressure, and others.

Methods and Materials:- The methanol extracts were prepared from powdered moringa stenopetala leaves. An antioxidant activity was measured hydrogen peroxide scavenging assays with UV-Vis spectrophotometer.

Results:- the scavenging activity values on hydrogen peroxide 20 $\mu \mathrm{g} / \mathrm{mL}$ of the extracts of moringa stenopetala leaves $84.188 \pm 0.386 \%$ increased than that of $40 \mu \mathrm{g} / \mathrm{mL}$ and $60 \mu \mathrm{g} / \mathrm{mL}$ were $59.96 \pm 0.122 \%$ and $46.995 \pm 0.088 \%$ respectively. Whereas decreased scavenging activity was exhibited at concentration of $60 \mu \mathrm{g} / \mathrm{mL}$. The maximum scavenging activity was exhibited for all concentration at 10 minutes. Conclusion:- the methanolic extract Moringa stenopetala leaves were a good scavenging activity by hydrogen peroxide when butylated hydroxytoluene as reference compound. Moringa stenopetala leaves can be used as a possibly for pharmaceutical applications

Copy Right, IJAR, 2016,. All rights reserved.

\section{Background:-}

An antioxidant is a chemical that prevents the oxidation of other chemicals. They protect the key cell components by neutralizing the damaging effects of free radicals, which are natural by- products of cell metabolism (Badarinath et al., 2010 and Milan et al., 2010). In the organism, hydrogen peroxide is generated by activated phagocytes used to kill several bacterial and fungal strains, additionally under physiological conditions by peroxisomes and oxidative enzymes. An increase in the rate of production or a decrease in the rate of removal disrupts this balance and increases the levels of reactive oxygen species and free radicals. This indicates harmful effects of free radicals and other oxidants (M. Rama et al. 2011 and Serhat et al., 2012). Free radicals are responsible for causing a large number of diseases including cancer, cardiovascular disease, neural disorders, alzheimer's disease, mild cognitive impairment, parkinson's disease, alcohol induced liver disease, ulcerative colitis, aging and atherosclerosis (Nur et al., 2013, Nooman et al., 2008 and Aurelia, M. P., and Gheorghe, P. N., 2011). The plants have a natural antioxidants scavenge harmful free radicals from our body (Ranju et al., 2009). In 2002 World Health Organization report, medicinal plants would be the best source to obtain a variety of drugs. In developed countries about $80 \%$ of plants are used in traditional medicine (Adamu et al., 2004). 
Hydrogen peroxide is a weak oxidizing agent and can inactivate a few enzymes directly, usually by oxidation of essential thiol (-SH) groups. It can cross cell membranes rapidly, and inside the cell, $\mathrm{H}_{2} \mathrm{O}_{2}$ probably reacts with $\mathrm{Fe}^{2+}$, and possibly $\mathrm{Cu}^{2+}$ ions to form hydroxyl radical which may be the origin of many of its toxic effects. Thus, the removing of $\mathrm{H}_{2} \mathrm{O}_{2}$ is very important for antioxidant defense in cell or food systems (Mahesh et al., 2010, Ranju et al., 2011 and Serhat et al., 2012).

Moringa plant family contains several phytochemicals and some of which are high interest because of their medicinal value (Mahesh et al., 2010). Moringaceae stenopetala is one of a species moringaceae, which have been found in Ethiopia. M. stenopetala is an important food and medicinal (heart failure, high blood pressure, and arrhythmia) plants that has been used for most southwestern Ethiopians, they called Aleco and/or Sheferaw. It is cultivated as a crop plant (Daljit et al., 2013). To quantify the antioxidant properties are important to human life. Therefore, Moringaceae stenopetala plants have been investigated for better understanding their medicinal properties.

Hence, the aim of this study was undertaken to evaluate the methanol leaves extract of moringa stenopetala for its antioxidant activity by using hydrogen peroxide scavenging method.

\section{Methods and Materials:- Sampling and Extraction:-}

The fresh mature leaves of moringa stenopetala were collected from in wolaita Sodo, southern Ethiopia, March 2014. The plant was authenticated by senior expert Botanists, Wolaita Sodo University, Ethiopia. The moringa stenopetala leaves was dried under shade and crushed to coarse powder and the powdered moringa stenopetala leaves was taken for soxhlet extraction using methanol as solvent. The extraction was done $20 \mathrm{~g}$ of dried powdered material was extracted with $150 \mathrm{~mL}$ of methanol for three hours. The obtained extracts were filtered over Whatman No. 1 paper and the filtrate was collected and the fraction after filtration was dried under reduced pressure to get the crude dried fraction. The yield of dried fraction of methanol extract of methanolic leaves extract of moringa stenopetala was collected for further analysis (Vibha et al., 2012, Ranju et al., 2011, M. Rama, P. and K. Vasantha, 2011, C. Senthil et al., 2010 and Serhat et al., 2012).

Hydrogen Peroxide Scavenging Capacity:-

The moringa stenopetala posse's potent antioxidant activity when compared with reference compound butylated hydroxytoluene (BHT). Hydrogen peroxide indirectly may enter into the human body through environmental contact. The ability of moringa stenopetala leaves extracts to scavenge hydrogen peroxide can be estimated according to the method of Ruch et al. (1989) stated by Nur et al. (2013), Keser et al. (2012), M. Rama et al. (2011), Ilhami et al. (2004) and etc. (Nur et al., 2013, M. Rama, P. and K. Vasantha, 2011, Serhat et al., 2012 and Ilhami et al., 2004).

$\%$ Scavenged $\left[\mathrm{H}_{2} \mathrm{O}_{2}\right]=[(\mathrm{AC}-\mathrm{AS}) / \mathrm{AC}] \times 100$

Where $\mathrm{AC}$ is the absorbance of the control and $\mathrm{AS}$ is the absorbance in the presence of the sample of $\mathrm{M}$. stenopetala extracts.

A solution of hydrogen peroxide (UNI-CHEM, $43 \mathrm{mM}$ ) is prepared in phosphate buffer (SAMIR TECH CHEM, 0.1 $\mathrm{M}, \mathrm{pH}$ 7.4). The absorbance's of hydrogen peroxide is determined by $230 \mathrm{~nm}$ using a Model $752 \mathrm{UV}$-Vis spectrophotometer. Extracts $(20,40$ and $60 \mu \mathrm{g} / \mathrm{mL})$ in distilled water is added to hydrogen peroxide and absorbances at $230 \mathrm{~nm}$ were determined five times in 10 min interval against a blank solution containing phosphate buffer without hydrogen peroxide. For each concentration, a separate blank sample was used for background subtraction. The values of percentage scavenging capacity were calculated for various concentrations of the extract. Tests were conceded out in triplicate.

\section{Statistical analysis:-}

The results of these investigations are means and standard deviation of three measurements. The different concentrations of extracts have significantly different efficiencies and times variation is significantly greater than the variation due to the random error of measurement were tested by two-way ANOVA. A p value of 0.01 was taken to be significant. 


\section{Results and Discussion}

The results of this study, Scavenging capacity of hydrogen peroxide in moringa stenopetala different concentration of $\mathrm{H}_{2} \mathrm{O}_{2}$ containing extract was also evaluated in a series of the 10 min period of the assay and BHT as reference compound was comparable shown below table 1 and figure $1.20 \mu \mathrm{g} / \mathrm{mL}$ methanol extracted moringa stenopetala exhibited $67.341-84.574 \%$ scavenging activity on hydrogen peroxide. On the other hand, using the same moringa stenopetala, $40 \mu \mathrm{g} / \mathrm{mL}$ and $60 \boldsymbol{\mu g} / \mathbf{m L}$ exhibited $50.50-64.336 \%$ and $30.412-47.083 \%$ hydrogen peroxide scavenging activity respectively. Scavenging activity of hydrogen peroxide in moringa stenopetala and BHT as reference compound was not remarkably different and shown to be $90.245 \%$ to $42.5 \%$.

Table 1:- hydrogen peroxide-scavenging activity of M. stenopetala leaves (20-60 $\mu \mathrm{g} / \mathrm{mL})$

\begin{tabular}{|c|c|c|c|c|c|c|}
\hline \multirow{3}{*}{$\begin{array}{l}\text { Time } \\
\text { minutes }\end{array}$} & \multicolumn{6}{|c|}{ Concentration in $\mu \mathrm{g} / \mathrm{mL}$} \\
\hline & \multicolumn{2}{|c|}{20} & \multicolumn{2}{|c|}{40} & \multicolumn{2}{|c|}{60} \\
\hline & MoS & BHT & MoS & BHT & MoS & BHT \\
\hline $\mathbf{0}$ & $82.927 \pm 0.028$ & $90.021 \pm 0.244$ & $50.124 \pm .074$ & $80.251 \pm 0.244$ & $30.66 \pm 0.148$ & $64.25 \pm 0.104$ \\
\hline $\mathbf{1 0}$ & $84.188 \pm 0.386$ & $86.321 \pm 0.841$ & $59.96 \pm 0.122$ & $74.897 \pm 0.215$ & $46.995 \pm 0.088$ & $60.895 \pm 0.112$ \\
\hline 20 & $67.391 \pm 0.050$ & $80.021 \pm 0.094$ & $55.134 \pm 0.166$ & $68.214 \pm 0.371$ & $37.535 \pm 0.053$ & $55.234 \pm 0.086$ \\
\hline 30 & $78.933 \pm 0.074$ & $78.952 \pm 0.132$ & $61.86 \pm 0.083$ & $66.135 \pm 0.098$ & $40.805 \pm 0.077$ & $48.216 \pm 0.064$ \\
\hline 40 & $79.282 \pm 0.070$ & $77.658 \pm 0.044$ & $64.298 \pm 0.038$ & $64.89 \pm 0.109$ & $39.173 \pm 0.024$ & $42.398 \pm 0.106$ \\
\hline
\end{tabular}

All the values are means of three independent determinations, $\mathrm{n} \pm \mathrm{Sd}$.

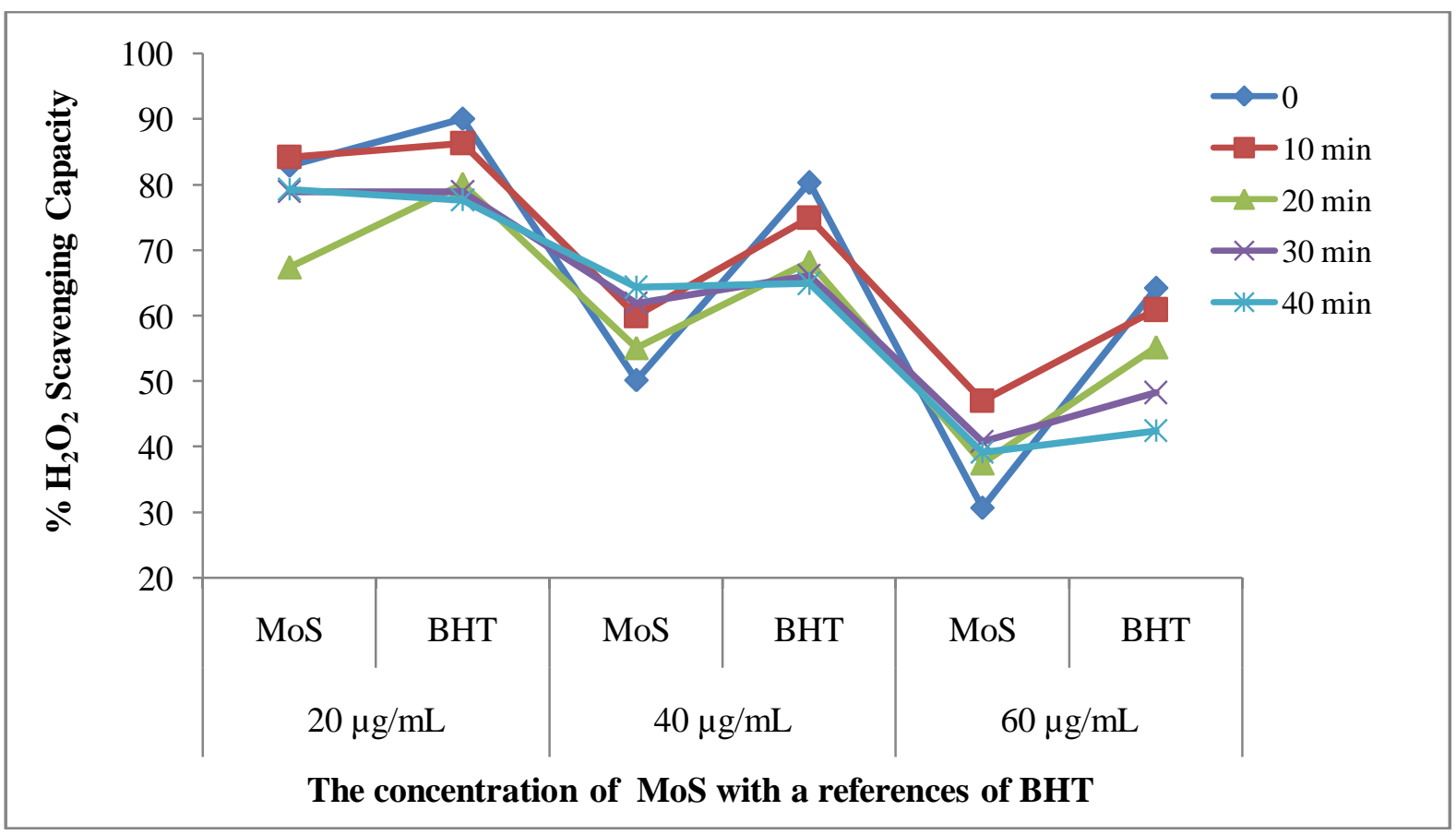

Figure 1:- Hydrogen peroxide scavenging activity of of moringa stenopetala

Results show that the scavenging activity values on hydrogen peroxide $20 \mu \mathrm{g} / \mathrm{mL}$ of the extracts of moringa stenopetala leaves increased than that of $40 \mu \mathrm{g} / \mathrm{mL}$ and $60 \mu \mathrm{g} / \mathrm{mL}$. Whereas decreased scavenging activity was exhibited at concentration of $60 \mu \mathrm{g} / \mathrm{mL}$. The maximum scavenging activity was exhibited for all concentration at 10 minutes. Therefore moringa stenopetala is biologically advantageous for cells to control the amount of hydrogen peroxide that is allowed to accumulate.

Moringa stenopetala has the antioxidant components and the highest $\mathrm{H}_{2} \mathrm{O}_{2}$ scavenging activity than Crataegus monogyna leaves, flowers and fruits in Turkey stated by Serhat et al., 2012. The two-way analysis of variances shows that, hydrogen peroxide scavenging activity was not a statistically significance between the concentration metanolic extract of M. stenopetala leaves whereas in the time interval was a statistically significance at $99 \%$ confidence interval. 


\section{Conclusions:-}

As a conclusion, the methanolic extract Moringa stenopetala leaves hydrogen peroxide scavenging and powerful total antioxidant activities when compared to and BHT as reference compound. The scavenging activity values on hydrogen peroxide $20 \mu \mathrm{g} / \mathrm{mL}$ of the extracts of moringa stenopetala leaves increased. The results of this study show that the methanolic extract Moringa stenopetala leaves can be used as easily accessible source of natural antioxidants and as a possible food supplement or in pharmaceutical applications.

\section{List of abbreviations:-}

BHT: butylated hydroxytoluene

MoS: Moringa stenopetala

Sd: Sstandard deviation).

\section{Acknowledgements:-}

This work was supported by Departments of Chemistry, Wolaita Sodo University, Ethiopia.

\section{References:-}

1. A.V. Badarinath K, Mallikarjuna RAo, C. Madhu Sudhana Chetty, S. Ramkanth, T.V.S Rajan, K.Gnanaprakash. A Review on In-vitro Antioxidant Methods: Comparisions, Correlations and Considerations, International Journal of PharmTech Research. 2010;22:1276-5.

2. Adamu HM, Abayeh OJ, Agho MO, Abdullahi AL, Uba A, Dukku HU and Wufem BM. An ethnobotanical survey of Bauchi State herbal plants and their antimicrobial activity, J. Ethnopharmacol. 2004;99:1-4.

3. Aurelia MP, and Gheorghe PN. Methods for Total Antioxidant Activity Determination: A Review, Biochemistry and Analytical Biochemistry. 2011;11:1-0.

4. Daljit S, Jemimah G and Harpreet K. Bioprospecting of Moringa (Moringaceae): Microbiological Perspective. Journal of Pharmacognosy and Phytochemistry. 2013;1:193-5.

5. M. Rama P and K. Vasantha. Antioxidant, Cytotoxicity and Polyphenolic Content of Calotropis procera (Ait.) R. Br. Flowers. Journal of Applied Pharmaceutical Science. 2011;17:136-0.

6. Mahesh GS, Paras P, Manish P, Samresh P and Asish N. Antidiarrheal Activity of Methanolic Extract of Moringa oleifera Lam Roots in Experimental Animal Models. International Journal of Pharmaceutical Research. 2010;22:35-9.

7. Milan C, Hana C, Petko D, Maria K, Anton S and Antonín L. Different methods for control and comparison of the antioxidant properties of vegetables. Food Control. 2010;21:518-3.

8. Nooman AK, Ashok KS, Atif A, Zaha E and Husni F. Antioxidant Activity of Some Common Plants. Turk Journal Biology. 2008;32:51-5.

9. Nur A, Nusrat $\mathbf{J}$ and B. Rafiquzzaman. Review on in vivo and in vitro methods evaluation of antioxidant activity. Saudi Pharmaceutical Journal. 2013;21:143-2.

10. Ranju P, Kundlik G, Nidhi S, Mohammed M and Thirumoorthy N. Antioxidant and free radical scavenging activity of ethanolic extract of Morinda citrifolia. Annals of Biological Research. 2011;21:127-1.

11. Ranju SP, G. Ariharasivakumar, Kundlik G and Ashutosh U. In -Vitro antioxidative activity of phenolic and flavonoid compounds extracted from seeds of abrus precatorius. International Journal of Pharmacy and Pharmaceutical Sciences. 2009; 12:136-0.

12. Vibha P, Pallavi S and Devendra G. A Comprehensive Study on Different Methods of Extraction from Guajava Leaves for Curing Various Health Problem. International Journal of Engineering Research and Applications. 2012;26:490-6.

13. C.Senthil K, B.Balamurugan, S.Murugeswaran, P. Natarajan, S.P.Sharavanan, S.Petchimuthu and S.Thiru S. Hepatoprotective Activity of Leaves and Roots Extracts of Moringa oleifera Lam. International Journal of Medicobiological Research. 2010;12:90-3.

14. Serhat K, Sait C, Semra T, Ökkes Y and Ismail T. Hydrogen Peroxide Radical Scavenging and Total Antioxidant Activity of Hawthorn. Chemistry Journal. 2012; 21:9-2.

15. Ilhami G, Ö.'Irfan K, Münir, O and Mehmet E. Antioxidant antimicrobial antiulcer and analgesic activities of nettle. Journal of Ethnopharmacology. 2004;90:205-5.

16. Pooja, Priyanka S, K.C.Samanta and Vikas G. Evaluation of nitric oxide and hydrogen peroxide scavenging activity Dalbergia Sissoo roots. Pharmacophore. 2010;12: 77-1. 